\title{
Crystallographic control on the substructure of nacre tablets
}

\author{
Antonio G. Checa ${ }^{\mathrm{a}, *}$, Harry Mutvei ${ }^{\mathrm{b}}$, Antonio J. Osuna-Mascaró ${ }^{\mathrm{a}}$, Jan T. Bonarski ${ }^{\mathrm{c}}$, Marek Faryna ${ }^{\mathrm{c}}$, \\ Katarzyna Berent ${ }^{\mathrm{c}}$, Carlos M. Pina ${ }^{\mathrm{d}}$, Marthe Rousseau ${ }^{\mathrm{e}}$, Elena Macías-Sánchez ${ }^{\mathrm{a}}$
}

\footnotetext{
${ }^{a}$ Departamento de Estratigrafía y Paleontología, Facultad de Ciencias, Universidad de Granada, Avenida Fuentenueva s/n, 18071 Granada, Spain

${ }^{\mathrm{b}}$ Department of Paleozoology, Swedish Museum of Natural History, Frescativägen 40, 11-418 Stockholm, Sweden

${ }^{\mathrm{c}}$ Institute of Metallurgy and Materials Science of the Polish Academy of Sciences, Reymonta. 25, 30-059 Kraków, Poland

${ }^{\mathrm{d}}$ Departamento de Cristalografía y Mineralogía, Facultad de Ciencias Geológicas, Universidad Complutense de Madrid, José Antonio Novais s/n, 28040 Madrid, Spain ${ }^{e}$ CNRS, UMR7365, Ingénierie Moléculaire et Physiopathologie Articulaire (IMoPA), Faculté de Médecine, Université de Lorraine, 9 Avenue de la Forêt de Haye, 54505

Vandoeuvre-lès-Nancy, France
}

\section{A B S T R A C T}

Nacre tablets of mollusks develop two kinds of features when either the calcium carbonate or the organic portions are removed: (1) parallel lineations (vermiculations) formed by elongated carbonate rods, and (2) hourglass patterns, which appear in high relief when etched or in low relief if bleached. In untreated tablets, SEM and AFM data show that vermiculations correspond to aligned and fused aragonite nano-globlules, which are partly surrounded by thin organic pellicles. EBSD mapping of the surfaces of tablets indicates that the vermiculations are invariably parallel to the crystallographic $a$-axis of aragonite and that the triangles are aligned with the $b$-axis and correspond to the advance of the $\{010\}$ faces during the growth of the tablet. According to our interpretation, the vermiculations appear because organic mol-ecules during growth are expelled from the $a$-axis, where the $\mathrm{Ca}-\mathrm{CO}_{3}$ bonds are the shortest. In this way, the subunits forming nacre merge uninterruptedly, forming chains parallel to the $a$-axis, whereas the organic molecules are expelled to the sides of these chains. Hourglass patterns would be produced by preferential adsorption of organic molecules along the $\{010\}$, as compared to the $\{100\}$ faces. A model is presented for the nanostructure of nacre tablets. SEM and EBSD data also show the existence within the tablets of nanocrystalline units, which are twinned on $\{110\}$ with the rest of the tablet. Our study shows that the growth dynamics of nacre tablets (and bioaragonite in general) results from the interac-tion at two different and mutually related levels: tablets and nanogranules.

Keywords: Nacre Molluscs Aragonite Crystallography Organic molecules

\section{Introduction}

The first crystallographic data on the nacre tablets were reported by Schmidt (1922), who concluded with optical microscopy that the $c$-axes of aragonite were perpendicular to tablets. In his subsequent papers,Schmidt $(1923,1924)$ used the outlines of tablets to infer the positions of $\{110\},\{100\}$ and $\{010\}$ faces and, hence, the orientations of the $a$ - and $b$-axes of the tablets. With the advent of the scanning electron microscopy, later authors e.g., (Grégoire, 1962; Wada, 1972; Mutvei, 1969, 1970, 1972a,brefined that knowledge, but the basic schemes provided by Schmidt remained essentially unaltered.

* Corresponding author. Fax: +34 958248528.

E-mail addresses: acheca@ugr.es (A.G. Checa),Harry.Mutvei@nrm.se (H. Mutvei), tay@ugr.es (A.J. Osuna-Mascaró), j.bonarski@imim.pl (J.T. Bonarski), marekfaryna@gmail.com (M. Faryna), marekfaryna@gmail.com (K. Berent), marekfaryna@ gmail.com (C.M. Pina), rousseam@gmx.net (M. Rousseau), emacias@ugr.es (E. Macías-Sánchez).
X-ray diffraction techniques are useful for determining crystal orientation, but its application is hindered by the fact that they can only determine the orientation of groups of tablets in relatively wide areas (at least $250 \mu \mathrm{m}$ in diameter). An additional handicap is that, due to the deep penetration of X-rays, the results combine data from dozens of superposed lamellae. Nevertheless, some insight can be gained. The distributions of maxima of pole figures indicate that in nacre tablets the $c$-axes are perpendicular to the main surfaces. Polarization-dependent imaging contrast (PIC), which is based on X-ray linear dichroism, has also been extensively applied to bivalve and gastropod nacres (Metzler et al., 2008; see review in Gilbert (2012)). It is a high resolution method $(\sim 20 \mathrm{~nm})$, but can only detect changes in the $c$-axis, and not in the $a$ - or $b$-axis. Additionally, the tablets of bivalves are known to be co-oriented, with the $b$-axis pointing in the local growth direction of the shell (Wada, 1961, 1972; Wise, 1970; Checa and Rodríguez Navarro, 2005; Rousseau et al., 2005). Tablet faces can sometimes be indexed by checking the shapes of the tablets against the overall orientation deduced from X-ray pole figures. Transmission electron microscopy (TEM) as well as electron 
back-scattered diffraction (EBSD) coupled to scanning electron microscopy (SEM) offer much higher resolution, but application is limited because the material has to be either sliced and thinned to tens of $\mathrm{nm}$, in order to make the sample transparent to ions for TEM, or sectioned and finely polished, to eliminate differences in relief, to which the EBSD technique is very sensitive. Since, the 3D aspect is lost in this way, it is difficult to relate the shape of the tablets to the orientations found. Therefore, electron diffraction techniques have been routinely used to determine crystallographic orientations only of sectioned nacre tablets (e.g., Gries et al., 2009; Dalbeck et al., 2006), but not in plain view.

In view of the above explanation, the main information currently available on the crystallography of individual nacre tablets is not always reliable, particularly taking into account their high variety of shapes (Wise, 1970; Wada, 1972; Checa and Rodríguez-Navarro, 2005).

In a number of informative papers, (Mutvei, 1970, 1977, 1978, 1979, 1980, 1991; Mutvei and Dunca, 2008, 2010), using special etching protocols, revealed the existence of two kinds of etching features. First, in the tablets of bivalves, gastropods and Nautilus, a series of parallel lineations that appear, are inferred to be parallel to the $a$-axis of aragonite. The same patterns have been found in other examples of biogenic aragonite which were naturally or artificially etched: foliated and prismatic aragonite (Checa et al., 2009). Second, in some bivalves (Mytilus, Nucula, and Unio), Mutvei (1977) found two triangular sectors on each tablet joined by a vertex at the center of the tablet (hourglass-like), which were more resistant to etching than the rest of the tablet. According to the interpretation of Mutvei $(1977,1978,1979,1980,1984)$, this pattern arose because each pseudohexagonal tablet was in fact composed by four twinned crystals, although this model (Mutvei, 1977, Fig. 1) was found to be incorrect by Akai and Kobayashi (1993).

The patterns revealed by Mutvei clearly have some bearing on the ultrastructure of nacre tablets and therefore are worth investigating. First, we needed to compile reliable data on the crystallography of individual nacre tablets in order to unequivocally relate the etching lineations and triangles to particular crystallographic directions. This was achieved by high-resolution diffraction techniques, particularly SEM-EBSD on the surfaces of the tablets. Additional information was gained from AFM and FESEM techniques. A model for the formation of the observed features was finally proposed.

\section{Materials and methods}

\subsection{Treatments}

Etching. Specimens were etched as originally described by Mutvei $(1977,1978,1979)$, the protocol consisting of (1) cleaning the tablets with sodium hydroxide, followed by (2) etching the tablets and fixing the organic matrix at the same time with a mixture of glutaraldehyde and acetic acid. Specimens were treated at the University of Granada with the following protocol: Sodium hypochlorite $10 \%$ (step 1 ) for $2-30 \mathrm{~min} \rightarrow$ glutaraldehyde $25 \%+$ acetic acid $1 \%$ in cacodylate buffer (step 2 ) for $2-10 \mathrm{~min} \rightarrow$ sodium hypochlorite $1 \%$ (step 3 ) for 1-5 days (optional). In all cases, samples were washed repeatedly and oven dried. Bivalves: Acila divaricata (Turtle Island, Taiwan), Nucula nitidosa (Málaga coast, Spain), Perna viridis (loc. unknown, Indonesia), Pinctada margaritifera (French Polynesia), Anodonta cygnea (Mira, Portugal); Gastropods: Bolma rugosa (Granada coast, Spain), Gibbula cineraria (Quiberon, France), Gibbula umbilicalis (São Jacinto, Portugal); cephalopod: Nautilus pompilus (loc. unknown).

The shells had been preserved dry and clean and we studied nacre areas which were not marginal. Etching intensity was proportional to treatment time (compare Fig. $1 \mathrm{~A}$ and $\mathrm{E}$ ), but it also varied between species undergoing the same treatment. No particular combination of times was found ideal for all species.

Additional observations were made at the Swedish Museum of Natural History on the nacre of the bivalve Mytilus edulis (coast of Sweden) and on the septal nacre of $N$. pompilius (Salomon Islands). These were treated with sodium hypochlorite (25 wt.\%) followed by immersion in Mutvei's solution (1:1 mixture of glutaraldehyde and $1 \%$ acetic acid to which alcian blue is added; see Schöne et al., 2005) under constant stirring at $35-40{ }^{\circ} \mathrm{C}$ and then dehydrated in graded alcohol concentrations.

In all cases, the exact treatment times are provided in the corresponding figure captions.

Protease. Samples of the bivalves A. divaricata (Turtle Island, Taiwan), Pinna nobilis (coast of Almería, Spain) and Pteria hirundo (Fuengirola, Spain) were incubated in a solution of proteinase-K (US Biological) 0.1 or $0.2 \mathrm{~g} / \mathrm{ml}$ for one to $2 \mathrm{~h}$ at $30^{\circ} \mathrm{C}$. After deproteinization, samples were washed three times for ten min under constant stirring in saline solution (PBS) and additionally washed for ten min in milli- $Q$ water. The samples were oven dried at $45^{\circ} \mathrm{C}$ and stored for later SEM examination.

Untreated and bleached samples. The nacres of the above-mentioned species, as well as those of the bivalves Atrina pectinata (Fuengirola, Spain), Anodonta anatina (River Thames, UK), Potomida littoralis (loc. unknown, Spain), Isognomon radiatus (Olango Island, Philippines) and Neotrigonia margaritacea (Anxious Bay, Australia) were also investigated intact, although in some cases the tablets were cleaned of organic matter with commercial bleach ( $4 \%$ active Cl) from 2 to $10 \mathrm{~min}$.

\subsection{Scanning electron microscopy (SEM)}

Samples were coated with carbon (Hitachi UHS evaporator) for FESEM observation (Zeiss Leo Gemini 1530 and Zeiss Auriga CrossBeam Station) at the Centro de Instrumentación Científica (CIC) of the Universidad de Granada (Spain). Specimens in Figs. 1B and 2E were gold-coated and photographed with a SEM Hitachi S-4300, at the Natural History Museum, Stockholm (Sweden).

\subsection{Electron back scattered diffraction (EBSD)}

To relate the crystallographic data with the features detected on the surfaces of the tablets, samples were analyzed unpolished with the surfaces of the tablets placed as parallel as possible to the detector screen; only the organic matter was removed with $5 \%$ $\mathrm{NaOCl}$ from the samples prior to analysis. Since this technique is very sensitive to surface irregularities, the percentage of indexable patterns dropped drastically compared to polished samples, although the number of available data provided relevant information. We used two sets of equipment. First, we used an Inca Crystal (Oxford Instruments) detector coupled to a Gemini-1530 (Carl Zeiss) FESEM (CIC, Universidad de Granada). To avoid excessive charging, samples were coated with a thickness of $2 \mathrm{~nm}$ of carbon in a Baltec MED 020 electron beam evaporator. Samples of the nacre from the gastropod $G$. cineraria and from the bivalves $A$. divaricata and P. margaritifera were examined in this way. Also, samples of the nacre of the bivalves Neotrigonia gemma (off Cronulla, Australia) and A. divaricata were analyzed after sectioning and polishing. The second set of equipment was a TSL OIM detector coupled to FEI Field Emission Gun (FEG) SEM Quanta 3D microscope of the Institute of Metallurgy and Materials Science of the Polish Academy of Sciences (IMIM, Krakow, Poland). Operation in low vacuum mode made coating unnecessary. A special cone was attached to the SEM pole piece to minimize the so-called "skirt effect" of the primary electron beam and reduce the gas-path length. Analysis software (TSL OIM version 5.3) was used to post-process the EBSD measurements. All data with a confidence index (CI) 

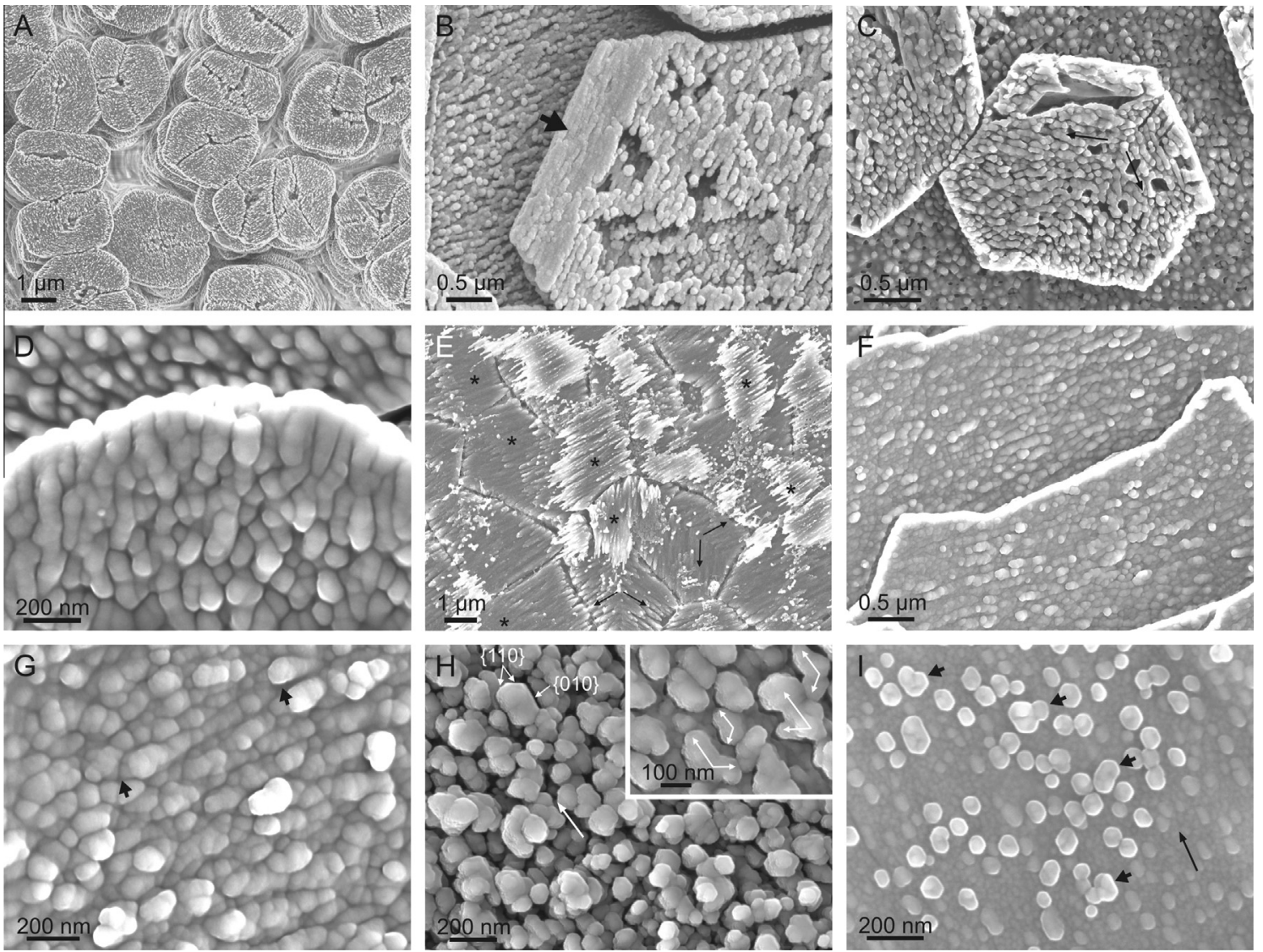

Fig.1. (A). Gibbula cineraria, treated with Mutvei’s protocol (step 1 for $10 \mathrm{~min}$, step 2 for $5 \mathrm{~min}$ ). Tablets are composed of several sectors with vermiculations at $\sim 120^{\circ}$. (B). Nautilus pompilius septal nacre, treated with 60 min with sodium hypochlorite and 120 min with Mutvei's solution. Note horizontal microlamination of the tablet, visible on the oblique edge (arrow). (C). Pteria hirundo, treated with protease $\left(0.1 \mathrm{~g} / \mathrm{ml}, 1 \mathrm{~h}\right.$ ). Note vermiculations diverging at $120^{\circ}$ (arrows), indicative of twinning. (D). Pteria hirundo, treated with Protease $(0.2 \mathrm{~g} / \mathrm{ml}, 1 \mathrm{~h}$ ). Close-up of the marginal area of a tablet showing vermiculations. (E). Pinctada margaritifera, treated with Mutvei's protocol (step 1 for $30 \mathrm{~min}$, step 2 for $10 \mathrm{~min}$, step 3 for five days). Vermiculations are arranged within planes, which in some instances (asterisks) are at an angle to the tablet surface. Some tablets display vermiculations at $\sim 120^{\circ}$ (double arrows). (F, G). Nautilus pompilius, bleached for 3 min. Note general arrangement of vermiculations. The close-up (G) clearly shows that the vermiculations are composed of fused carbonate nanogranules. The two arrows indicate the ends of one such vermiculation ( $\mathrm{H}$ ). Nautilus pompilius, bleached for $2 \mathrm{~min}$. The nanogranules on the surface of the tablet have pseudohexagonal shapes. The indexation is tentative. The inset shows several fused pseudohexagons which seem to diverge at $\sim 60^{\circ}$ or $120^{\circ}$ (arrows), thus suggesting nanotwinning. The long arrows indicate the main orientation of the vermiculations. (I). Pinctada margaritifera, bleached for $10 \mathrm{~min}$. Many nanocrystals, some of which are clearly composite or twinned (arrows), appear on the surface. The long arrow indicates the orientation of the $a-$ axis (same specimen as in Fig. 3C).

below 0.1 were removed. For visualization purposes the following cleanup procedure was applied: (1) grain CI standardization, (2) neighbor orientation correlation, (3) neighbor $\mathrm{CI}$ correlation. The surfaces of nacre tablets of the bivalves A. divaricata, Pt. hirundo, and $P$. nobilis were examined with this second equipment.

\subsection{Atomic force microscopy (AFM)}

For AFM observations, a sample of the shell of $P$. margaritifera was polished, through a protocol adapted from Nouet et al. (2012). We used Struers water-grinding papers (DP Mol and DP Dur), followed by a thin polishing with Struers diamond pastes $(3,1$, and $0.25 \mu \mathrm{m})$ and finally silica gel suspension $(\sim 3 \mathrm{~h})$. The sample was etched in a $0.1 \mathrm{wt} . \%$ acetic acid with $3 \%$ glutaraldehyde solution for $8 \mathrm{~s}$. It was later repolished, immersed in commercial bleach for $\sim 90 \mathrm{~s}$ and dried before placing in the AFM sample holder. In addition, the surfaces of nacre tablets (bleached or protease-treated) of the following taxa were examined: the bivalves P. margaritifera, P. nobilis, A. pectinata, A. divaricata, A. anatina, P. littoralis, I. radiatus, N. margaritacea, and Pt. hirundo, the gastropod $B$. rugosa, and the cephalopod $N$. pompilius. Observations were made both in air and liquid using an AFM (Multimode Veeco) of the Centro Nacional de Microscopía Electrónica (Universidad Complutense de Madrid, Spain). AFM images were recorded in both contact and tapping modes while displaying cantilever height, phase and amplitude signals. Recorded AFM images were subsequently analyzed using the Nanoscope 5.30r3sr3 and Nanotec WSxM. 2.1 software's (Horcas et al., 2009).

\section{Results}

\subsection{SEM}

All etched and protease-treated samples (with the exception of P. nobilis) displayed more or less conspicuous lineations, similar to those found by Mutvei $(1977,1978,1979,1980)$ and Mutvei and Dunca $(2008,2010)$ (Fig. 1A-D). Lineations ran mutually parallel across the entire tablet diameter. There appeared to be some direct relationship between etching time and lineation development, but some species proved more susceptible to the treatment than others. In non-etched samples, where the boundaries between lineations could be established with some precision, they range in width between $\sim 40$ and $120 \mathrm{~nm}$. Lineations sometimes fused or divided, finally displaying a sinuous path. For this feature, we will call them vermiculations hereafter (Fig. 1A-G; one vermiculation is marked with arrows in Fig. 1G). Gastropod tablets are sometimes 

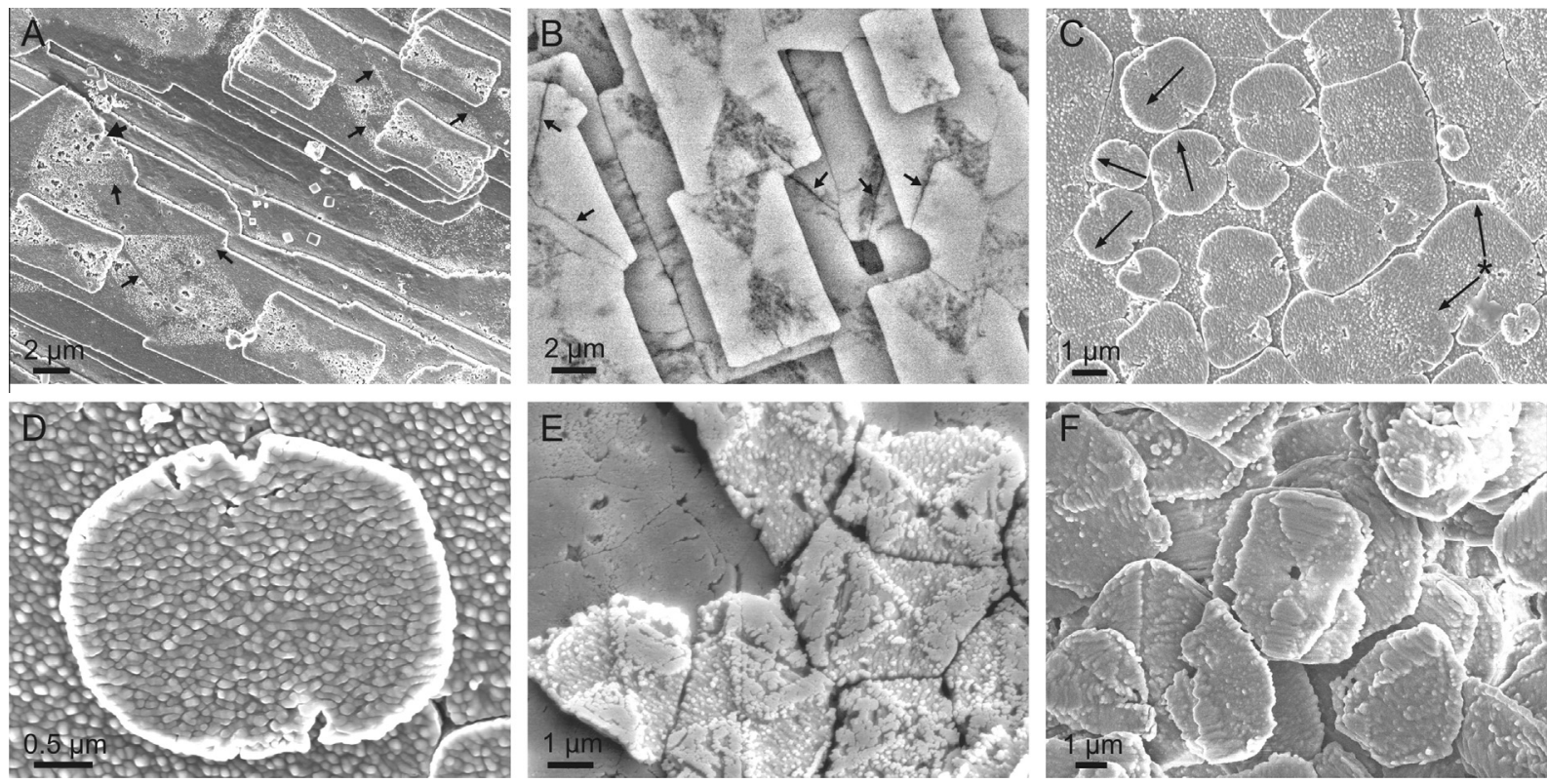

Fig.2. (A, B) Rectangular nacre tablets of Pinna nobilis, treated with Protease $(0.2 \mathrm{~g} / \mathrm{ml}, 1 \mathrm{~h})$. Secondary electron (A) and back scattered electron (B) images. Hourglass patterns (although no apparent vermiculations) form upon treatment. Interpenetration boundaries between tablets (arrows) are parallel to the long sides of triangles; they are particularly apparent in (B). (C and D) Pteria hirundo, treated with Protease $(0.2 \mathrm{~g} / \mathrm{ml}, 1 \mathrm{~h})$. Treatment causes the formation of small triangular notches and well-developed vermiculations. In (C), the orientations of vermiculations in some tablets are marked with arrows; they have a three-rayed distribution, indicative of $\{110\}$ twinning; the tablet marked with an asterisk has two sectors with vermiculations at $120^{\circ}$. (E) Mytilus edulis, treated with sodiumhypochlorite for 30 min and Mutvei's solution for 3 min. Note vermiculations in addition to hourglass features. (F) Gibbula umbilicalis, treated with Mutvei's protocol (step 1 for 30 min, step 2 for 10 min, step 3 for five days). Tablets are monocrystalline. This is the only case of a gastropod in which hourglass patterns (in high relief) were discerned.

divided into different sectors, with their vermiculations meeting at angles of $\sim 60^{\circ}$ or $120^{\circ}$ (Fig. 1A). Nautilus (Fig. 1B) and bivalve tablets (Fig. 1C-E) were mostly undivided into sectors and only rarely consisted of two sectors at the most, with vermiculations at $\sim 120^{\circ}$.

In etched samples, vermiculations could be either strictly parallel or slightly inclined with respect to the surface of the tablet (Fig. 1E). In the latter case, the angles of inclination could not be estimated quantitatively.

Some of the untreated and slightly bleached (Fig. 1F and G) samples had more or less conspicuous surface relief consisting of aligned globular nanogranules $(20-120 \mathrm{~nm}$ in diameter) running along the entire tablet diameter. The alignments showed exactly the same pattern of irregularities and sizes as the vermiculations observed in treated samples. In some instances, the nanogranules found at the very surface of the tablets grew in isolation and showed neat pseudohexagonal outlines; they can thus be qualified as nanocrystals (Fig. $1 \mathrm{H}$ and I). These nano-pseudohexagons might be larger than the nanogranules (up to $200 \mathrm{~nm}$ ) and sometimes diverged at $\sim 60^{\circ}$ or $120^{\circ}$, suggesting that they are nanotwinned units (Fig. $1 \mathrm{H}$, inset, and $\mathrm{I}$ ).

The samples of $P$. nobilis and Pt. hirundo treated with protease displayed typical hourglass patterns in low relief. $P$. nobilis tablets have an unusual rectangular shape (shown by Wise, 1970; Wada, 1972) and the triangular areas were distributed along the maximum dimensions of the tablets with a corroded aspect (Fig. 2A and B). In Pt. hirundo these areas aligned with the short axis of the oval tablets, consisting of incipiently developed triangular notches (Fig. 2C and D). In P. nobilis, when two tablets in the same orientation met and intersected, the resulting boundary was invariably parallel to the sides of the triangles (Fig. 2A and B). In addition to dissolution triangles, the sample of Pt. hirundo showed a surface relief of vermiculations, with their overall elongation perpendicular to the axis joining the two triangular sectors (Fig. $2 \mathrm{C}$ and D). The similarly treated sample of $A$. divaricata only showed vermiculations of the kind found in etched samples. Similar triangular hourglass sectors were visible in etched samples of $M$. edulis (Fig. 2E) and G. umbilicalis (Fig. 2F), differing in that the acute triangles developed in high relief due to preferential dissolution of the calcium carbonate instead of the organic fraction. In both cases, the treatment also produced vermiculations which, as in the protease-treated samples, ran perpendicular to the axis joining the acute triangles (Fig. 2E and F). It bears noting that triangular sectors were not found in the bivalves $P$. viridis, A. divaricata, and $A$. cygnea, in the gastropods $B$. rugosa and $G$. cineraria, and in the cephalopod N. pompilus. Mutvei (1977) reported them also in the bivalve Nucula sulcata.

\subsection{SEM-EBSD}

The results for tablets showing vermiculations, regardless of whether they were etched (A. divaricata, $N$. nitidosa), treated with protease (Pt. hirundo) or simply bleached ( $P$. margaritifera), and regardless of whether or not they displayed triangular patterns at the same time, were all consistent. The 001 maxima of the associated pole figures were more or less centered on the diagrams and the 100 maxima were aligned with the vermiculations, or with the alignments of nanogranules (Fig. 3A). Some minor 100 maxima also appeared at $\sim 60^{\circ}$ from the main maxima. This implies that the $c$-axis was approximately perpendicular or at a high angle to the tablets and that the $a$-axis was parallel to the vermiculations. The 100 small maxima at $60^{\circ}$ of the main maximum or maxima are indicative of some small crystals being twinned on $\{110\}$.

The map on the protease-treated sample of $P$. nobilis is, by far, the one which gave the best-quality results (Fig. 3B). Despite the lack of vermiculations, the triangular sectors were clearly aligned with the 010 maxima, i.e., the $b$-axis of aragonite. In addition to the main maxima (clustered within the NE and SW quadrants in Fig. 3B), there were two diffuse 010 maxima (NW quadrant), all three clusters being at $\sim 60^{\circ}$ to each other. One of these corresponds to dots in dark blue which appeared scattered onto the 

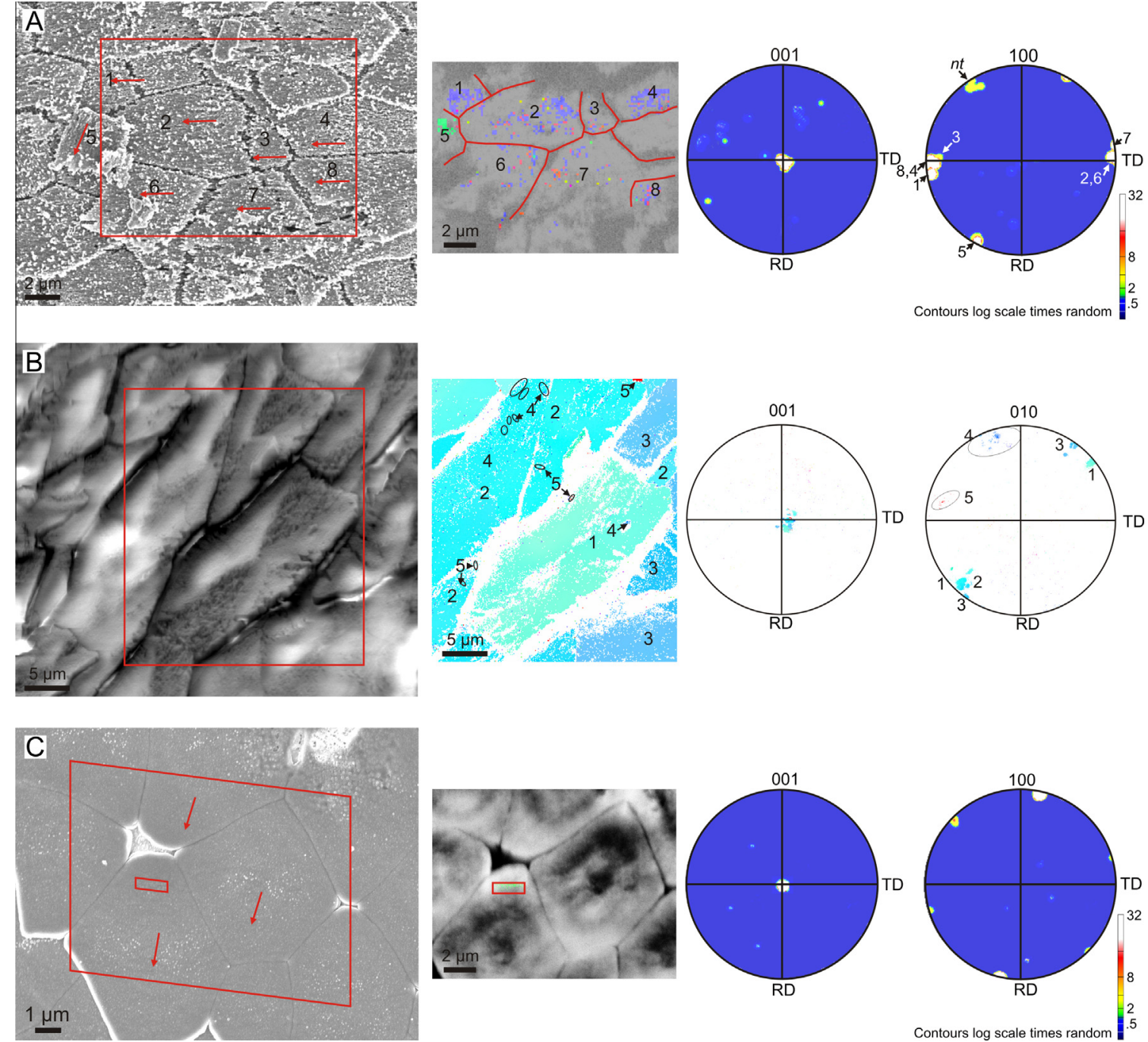
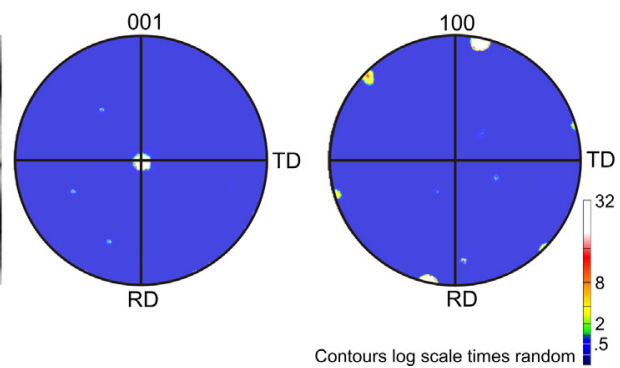

Fig.3. EBSD maps of (A) Acila divaricata, treated with Mutvei's protocol (step 1 for 4 min, step 2 for 2 min), (B) Pinna nobilis, treated with protease (0.2 g/ml, 1 h), and (C) Pinctada margaritifera, bleached for $10 \mathrm{~min}$. In all cases, the left image is the secondary electron image (with indication of the mapped area, red quadrangle, and orientation of the vermiculations, red arrows), the center image is the orientation map and the right diagrams are the 001 and 100 (A, C) or 010 (B) pole figures of aragonite. Numbers in (A) and (B) correspond to particular crystal domains or nanodomains. In all three cases, the 001 maximum is at or close to the center of the diagram (i.e., the $c$-axis is perpendicular to the tablet surfaces). The maximum spread of 001 maxima for individual tablets is $6^{\circ}(\mathrm{A}), 12^{\circ}(\mathrm{B})$ and $2^{\circ}(\mathrm{C})$; the total spread for 001 maxima is $22^{\circ}(\mathrm{A})$ and $25^{\circ}(B)$. In (A) and (C), the distribution of 100 pole maxima implies that the $a$-axes of aragonite crystals are parallel to the vermiculations. In (A), an additional 100 small maximum (labelled $n t$ ) at $\sim 60^{\circ}$ to the other maxima indicates the existence of twinned nanocrystals. In (B), the $b$-axis is aligned with the triangular corrosion sectors; some scattered analyses (labeled 4 and 5 in the orientation map) have their 010 maxima at $\sim 60^{\circ}$ to the main maxima $(1,2$ and 3$)$ and can again be interpreted as nanocrystals twinned with the main tablets. RD, rolling direction; TD, transverse direction.

nacre tablets. The other maximum (made of red dots) was provided by a small tablet (top edge of the orientation map in Fig. 3B, labeled 5) together with additional scattered dots (Fig. 3B). Scattered dots in both dark blue and red are indicative of nanocrystals twinned on $\{110\}$ with the tablets onto which they settled. Similar results were found on a bleached sample of $P$. margaritifera (Fig. 3C), in which the nanogranules were aligned with the $a$-axis and the triangular sectors made by nanogranules in high relief (a close-up view of those nanogranules in this same sample is shown in Fig. 1I) were aligned with the $b$-axis. Note also two tiny additional 100 maxima at $\sim 60^{\circ}$ to the main maximum (aligned NNE-SSW), which imply that some nanogranules (independent dots not shown, but contained in the minor maxima) are related with the rest of the tablet (main maximum) by a $\{110\}$ twinning.

\section{3. $A F M$}

The observation of tablets of the observed species has shown that the surfaces of tablets are in all cases made of round granules with diameters similar to those observed with SEM ( 20-120 nm) (Fig. 4). These units are surrounded by a pellicle (Fig. 4F, G, J and K), which in phase mode contrasts sharply with the granules (Fig. 4E, $\mathrm{H}$ and $\mathrm{L}$ ). The pellicles had different degrees of preservation depending on the original state of the samples and on the treatments, from being almost continuous around the granules (e.g., Fig. $4 \mathrm{~K}$ ), to be reduced to a narrow rim along the depressed edges between and within grains (Fig. $4 \mathrm{~F}$ and $\mathrm{G}$ ). In some tablets the granules showed no preferential alignment, whereas in others they coalesced, forming alignments of variable width (between 40 and $120 \mathrm{~nm}$ ) (Fig. 4). When the pellicles were poorly developed, they surrounded the aligned sets of granules (Fig. 4C, D, G and H). Etching revealed tablet elongation along the $a$-axis in the septal nacre of $N$. pompilius (Fig. 4A-F), while elongation along the same crystallographic axis was obtained via simultaneous analysis with FESEM-EBSD in the nacre of Pt. hirundo (Fig. 4G-L). For this reason, we know that in both cases the alignments of nanogranules detected with AFM are parallel to the crystallographic $a$-axis of the tablet. 

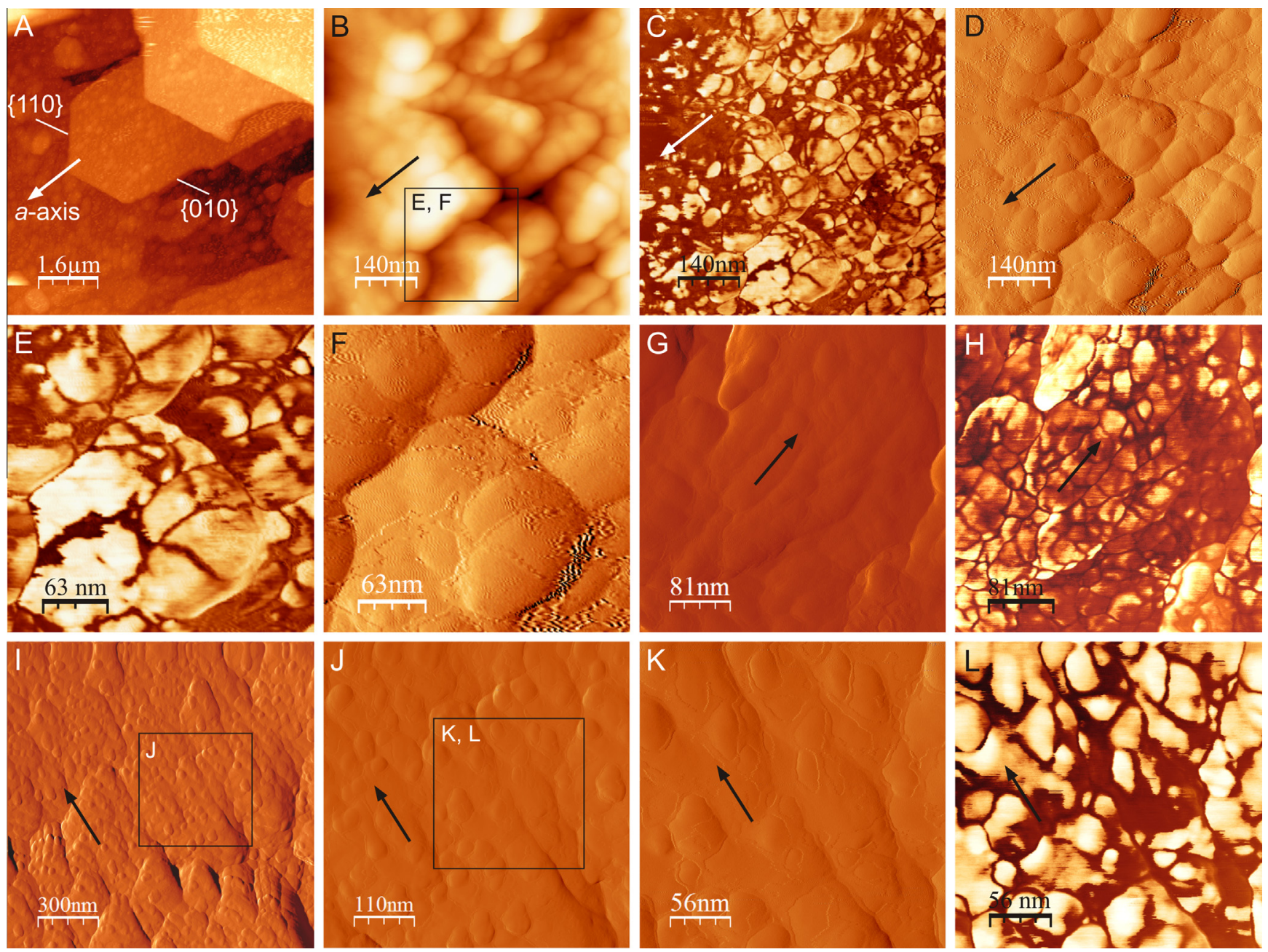

Fig.4. AFM views of nacre. (A-E) Septal nacre of Nautilus pompilius (untreated). (A) Height image of three superposed tablets, with some faces indexed. (B-D) Height (B), phase (C) and amplitude (D) images of a close-up of (A). Note alignment of nanogranules in parallel to the $a$-axis of the tablet (arrows). (E and F) Phase (E) and amplitude (F) images of a magnified region of $B$ (framed in B) showing the organic pellicles. (G-L) Pteria hirundo, treated with protease $(0.2 \mathrm{~g} / \mathrm{ml}, 1 \mathrm{~h})$. (G, H) Amplitude $(\mathrm{G})$ and phase image $(\mathrm{H})$ of an area in which organic membranes are reduced to the boundaries between nanogranules, which appear fused and aligned (arrows). The distribution of organic membranes can be better appreciated in the phase image. (I-L) Amplitude (I-K) and phase (L) images showing progressive magnifications (frames) of an area in which nanogranules are aligned (arrows). Note relatively good preservation of organic nanomembranes in (K) and (L).

\section{Discussion}

Our FESEM and AFM observations showed that nacre tablets have a granular substructure, with granules ranging in size from 20 to $120 \mathrm{~nm}$. Under FESEM, they have a globular aspect (Fig. $1 \mathrm{E}$ and $F$ ), although those located at the tablet surface sometimes tend to develop crystalline outlines (Fig. $1 \mathrm{H}$ and I). Similar nanocrystallites were observed on the surfaces of tablets by Metzler et al., 2008; Mutvei and Dunca, 2010) and were observed in sectioned mature nacre with TEM (Checa et al., 2011, figures 2 and 3), which excludes that they are artefacts arising during preparation (e.g., immersion in hypochlorite). AFM observations allow us to recognize that, in addition, the amalgamated granules are in turn surrounded by pellicles(Fig. $4 \mathrm{E}-\mathrm{H}$ and $\mathrm{J}-\mathrm{L}$ ). This granular substructure was revealed for the first time by Dauphin (2001) in the nacre of Nautilus. Her AFM results were later amply confirmed with the same technique in the nacre of bivalves and gastropods ( $\mathrm{Li}$ et al., 2004, 2006; Bruet et al., 2005; Rousseau et al., 2005; Wolf et al., 2012). Dauphin (2008) found this to be a general property of calcitic and aragonitic materials secreted by mollusks, as recognized later in a variety of other invertebrate animals (sponges, Sethmann et al., 2006; corals, Przeniosło et al., 2008; and echinoderms, Seto et al.,2012) and even in fish otoliths (Dauphin and Dufour, 2008).

The great contrast in AFM tapping mode (phase imaging) between the pellicles and calcium carbonate granules (Fig. 4C, E, H and $\mathrm{L}$ ) has led some authors to hypothesize that the former are organic in nature (e.g., Dauphin, 2001, 2006; Bruet et al., 2005; Rousseau et al., 2005; Li et al., 2006; Baronnet et al., 2008). Li et al. (2006) even showed how rotation of nanoparticles was favoured by the intervening polymer biofilms when nacre was subjected to tension. Based on former TEM data for nacre by Nassif et al. (2005), Seto et al. (2012) alternatively proposed that similar pellicles in the sea urchin test might consist of ACC. Our own bleaching experiments (unpublished observations) conducted with AFM are consistent with the organic nature of pellicles.

In many cases, the nanogranules tend to be preferentially aligned, thus forming vermiculations which are several $\mu \mathrm{m}$ in length (Fig. 1F and G). Our EBSD data (Fig. 3A and C) imply that the vermiculations observed in the treated samples (Fig. 1A-D) consistently occur along the $a$-axis of aragonite. This conclusion was previously reached by Mutvei (1970), although here we provide direct crystallographic evidence. Once the orientation of the $a$-axis is known, the crystal faces of the nanogranules can 
tentatively be indexed (Fig. 1H). Given the coincidence in size, morphology, and crystallographic orientation, it is evident that the vermiculations observed in slightly bleached or untreated samples are the precursors of those observed in etched or proteasetreated samples.

EBSD pole figures (Fig. 3) show that in our samples the $c$-axis is perpendicular or at a big angle to the surfaces of the tablet, although some deviation of the tablet surfaces with respect to the stage surface was expected. When several tablets are measured (Fig. $3 \mathrm{~A}$ and $\mathrm{B}$ ) the spread increases (to $>20^{\circ}$ in Fig. $3 \mathrm{~A}$ and $\mathrm{B}$ ), which implies that there are some differences in the orientation of the $c$-axes of neighboring tablets. Similar EBSD-based results have been obtained in the sectioned nacres of some bivalves by Dalbeck et al. (2006), England et al. (2007), Freer et al. (2010) and Griesshaber et al. (in press). Even higher spreads have been recorded with the PIC technique by the Gilbert group (Metzler et al., 2007; Gilbert et al., 2008; Olson et al., 2012, in press) in bivalves and gastropods, this being particularly high at the transition with the external shell and gradually diminishing away from this limit.

Based on our observations, we propose that nacre tablets consist of amalgamated vermiculations, i.e., fused calcium carbonate granules, which are aligned approximately parallel to the $a$-axis of the tablet. When the fused units grow isolated on the surface of the tablet, they are loosely packed and tend to develop crystalline shapes, because they grow within the proteinaceous material lining the interlamellar layer on both sides. These are the so-called hillocks or nanoasperities observed on the surfaces of nacre tablets (see Checa et al., 2011, figures 2 and 3) and correspond to the coarse granular layer of Mutvei and Dunca (2008, 2010). Vermiculations are bounded and separated from each other by nanometric organic pellicles, of the kind visualized with AFM (Fig. 4), althoughthis may not be the only organic fraction involved. This substructure is most probably general to biogenic aragonite formed by mollusks, since similar etching lineations along the $a$-axis have also been reported in foliated and prismatic aragonite (Checa et al., 2009). These authors explained these features as the result of organic molecules being expelled from more mineralized zones along the $a$-axis by the crystallization pressure. This happens because, in the aragonite structure, there are chains of strong bonds along the $a$-axis, where the distance between the Ca atoms and the $\mathrm{CO}_{3}$ groups is the shortest. The expelled organic molecules can easily be incorporated along the other crystallographic directions, where either the $\mathrm{Ca}-\mathrm{CO}_{3}$ distances are larger (b-axis) or the stacked $\mathrm{CO}_{3}^{=}$groups are bonded by weak Van der Waals forces (c-axis) (Nelyubina and Lyssenko, 2012, and references therein). Our observations enable us to refine this model. Present-day models imply that biocrystals are formed from an amorphous calcium carbonate (ACC) precursor due to secondary nucleation (Politi et al., 2008; see also Weiner and Addadi, 2011; Gong et al., 2012, and Cartwright et al., 2012). In mollusks, good evidence has been presented by Nassif et al. (2005), who reported the existence of an ACC layer between 3 and $5 \mathrm{~nm}$ around nacre tablets of the abalone Haliotis laevigata, and by Baronnet etal. (2008), who showed how an ACC cortex of $\sim 40-60 \mathrm{~nm}$ carpets the growth surface of the calcitic prisms of the pearl oyster $P$. margaritifera. In line with the observations of Nudelman et al. (2007) (who observed similar granules attaching to the surface of the calcitic prisms of Atrina rigida) and of Baronnet et al. (2008) (who, by TEM, identified grains comparable to the granules seen under AFM crystallizing at the growth front of prisms from the ACC layer), we can consider the granules making up the vermiculations to be crystallization units (although this is not critical for our explanation). This idea is consistent with the model of Weiner and Addadi (2011, figure 3) for the crystallization of the sea urchin spicule. During growth, theconnections between granules in the direction of the $a$-axis will go uninterrupted because organic molecules (probably exsolved from the ACC by the crystallization force) cannot easily enter the crystal lattice in this direction, but would be absorbed preferentially at the boundaries between granules corresponding to adjacent vermiculations, which is on the $\{010\}$ faces (perpendicular to the $b$-axis) (Fig. 5). Vermiculations have not been detected in some of the species (e.g., P. nobilis, Fig. 2A and B, or in the central part of the tablets of Pt. hirundo, Fig. 2C and D), which may be due to either defective treatment or (general or local) deficiency in the absorbableorganic fraction.

SEM-EBSD data demonstrate that tablets displaying etching or bleaching triangles (Fig. 3), are single crystals, with the triangles being aligned with the $a$-axis if they develop upon acidic treatment (Fig. 2E and F), or with the $b$-axis if the triangles become excavated upon treatment with bleach or protease (Figs. 2A-D and 3B). The apical angle is $\sim 60^{\circ}$, which implies that the long sides of triangles correspond to traces of $\{110\}$ faces of aragonite. In P. nobilis, when two rectangular tablets collide and begin to interpenetrate, the boundaries thus formed are also parallel to the $\{110\}$ faces (Fig. 2A and B). This happens because the side relations of the rectangular tablets of this species agree to the $a / b$ cell lattice relation of

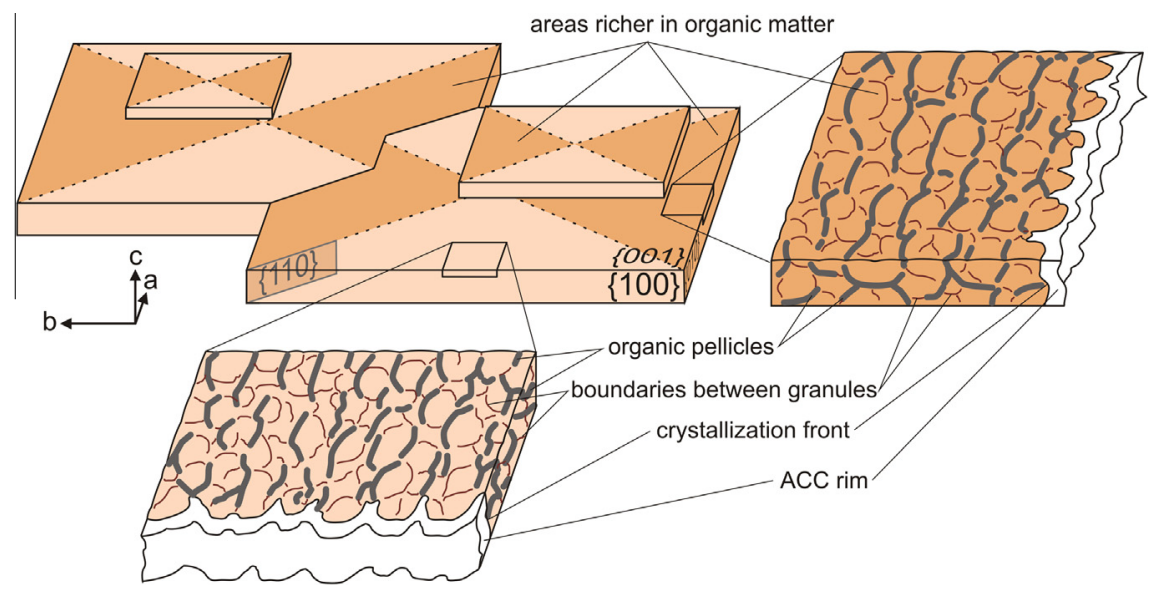

Fig.5. Model for the internal structure of ideal nacre tablets. They are composed of four growth sectors, with the sectors corresponding to the growth of $\{010\}$ faces being richer in organic matter. Internally, the material is composed of calcium carbonate granules aligned in parallel to the crystallographic $a$-axis of aragonite (vermiculations). The organic pellicles surrounding the granules distribute preferentially around the lateral boundaries of the vermiculations. The sketch reproduces the case of the rectangular tablets of Pinna nobilis, and is based on the hypothesis that aragonite crystallizes from an amorphous calcium carbonate (ACC) precursor, with the granules being the crystallization units. 
aragonite $4.959 / 7.968=0.622$. The fact that the triangular sectors remain in high relief upon etching (Fig. $2 \mathrm{E}$ and $\mathrm{F}$ ), while they dissolve preferentially with protease (Fig. 2A-D), clearly implies that these areas are richer in organic matter than is the rest of the tablet. Since these triangles correspond to the advance of the $\{010\}$ faces during the growth of the nacre crystal, the immediate implication is that there is preferential adsorption of organic molecules along the $\{010\}$ faces. Since none of the two mentioned sets of faces display significant differences in charge density, the only reasons we can invoke are similar to the ones above to explain the vermiculations, i.e., differences in the length of the bonds along the $a$ - and $b$-axes. The lack or etching or dissolution triangles in some of the treated species (see above) may imply that the absorbable proteinaceous component may be lacking.

The processes of preferential absorption of organic molecules along the $b$-axes, as compared to the more reduced absorption along the $a$-axes, commented on above to explain the observed vermiculations, could happen anywhere around the tablet, with the difference being that the amount of organic matter to be redistributed around growing nanogranules would be greater within the growth sectors of $\{010\}$ faces than within the sectors of the $\{100\}$ faces (Fig. 5). In this work, we focus on the nanomembranes examined with AFM, although this may not be the only organic component within the tablets. Younis et al. (2012) have imaged occluded macromolecules within the nacre of the mytilid Perna with TEM tomography, which are scattered within the crystals and have much larger dimensions than do the organic membranes observed with AFM. Similar organic components have been detected in the prismatic calcite of the bivalves Pinctada and Atrina (Okumura et al., 2010, 2011; Li et al., 2011). How the different intracrystalline organic components are absorbed is a matter of future study. Younis et al. (2012), Li et al. (2011) and Gilow et al. (2011) showed that the organic macromolecules are preferentially absorbed on the $\{001\}$ planes in nacre and prismatic calcite due to preferential binding of the negatively charged residues of the acidic proteins to the positively charged $\{001\}$ calcium planes. This might explain the horizontal microstratification sometimes shown by nacre tablets (Fig. 1B; see also Mutvei and Dunca, 2010).

Our EBSD data indicate the existence of nano-crystals twinned on $\{110\}$ which appear scattered both on the surface (N. pompilius, Fig. $1 \mathrm{H}$; P. margaritifera, Fig. 1I) and within the interior of tablets (etched tablets of Nucula, Fig. 3A, and protease-treated tablets of Pinna, Fig. 3B, as well as sectioned tablets of Neotrigonia and Acila, unpublished data). Nanocrystals of the external surface of tablets with the aspect of being twinned appear in the bleached nacre of N. pompilius (Fig. 1H) and P. margaritifera (Fig. 1I) under SEM. Nacre tablets and biocrystals in general are made of crystallographically oriented nanoparticles. Li and Huang (2009), Huang and Li (2012) and Zhang and Li (2012) identified nanoparticles via TEM and observed that, despite the fact that tablets of nacre diffract as single crystals, the constituent nanoparticles (which they implied are aggregation units) showed noticeable degrees of mutual misorientation (pseudo-single-crystal effect). The oriented arrangement could be transformed into a disoriented aggregate by either heat treatment (without phase change) or deformation (Huang and $\mathrm{Li}$, 2012). Any hypothesis on the mode of aggregation and growth of biocrystals (e.g., from an amorphous precursor; see above), has to take into account the new degree of freedom that the existence of the recognized internal nanotwins implies.

Our study shows that the growth dynamics of nacre tablets (and bioaragonite in general) is much more complex than previously supposed, and that it results from the interaction at two different and mutually related levels: tablets and their constituent nanogranules (the monocrystal-polycrystal duality of Li and Huang, 2009; Huang and Li, 2012).

\section{Acknowledgments}

Antonio Sánchez-Navas (Dept. Mineralogy and Petrology, Univ. Granada) provided essential advise on the crystallography of nacre. A.G.C. A.J.O.-M., C.M.P. and E.M.-S. received funding from projects CGL2010-20748-CO2-01 of the Spanish Ministerio de Ciencia e Innovación and RNM6433 of the Andalusian Consejería de Innovación Ciencia y Tecnología, as well as from the Research Group RNM363 (latter institution) and the European COST Action TD0903 (EU). A.G.C. and C.M.P. also acknowledge the Centro de Instrumentación Científica (Univ. Granada) and the Centro Nacional de Microscopía Electrónica (Univ. Complutense Madrid), respectively, for the use of the equipment. Comments from two anonymous reviewers helped to improve the manuscript.

\section{References}

Akai, J., Kobayashi, I., 1993. Microtwinning in the aragonitic shell layers of molluscs observed by TEM. In: Kobayashi, I., Mutvei, H., Sahni, A. (Eds.), Structure, formation and evolution of fossil hard tissues. Tokai University Press, Tokyo, pp. $47-54$.

Baronnet, A., Cuif, J., Dauphin, Y., Farre, B., Nouet, J., 2008. Crystallization of biogenic Ca-carbonate within organo-mineral micro-domains. Structure of the calcite prisms of the Pelecypod Pinctada margaritifera (Mollusca) at the submicron to nanometre ranges. Mineral. Mag. 72, 617-626.

Bruet, B.J.F., Qi, H.J., Boyce, M.C., Panas, R., Tai, K., et al., 2005. Nanoscale morphology and indentation of individual nacre tablets from the gastropod mollusc Trochus niloticus. J. Mater. Res. 20, 2400-2419.

Cartwright, J.H.E., Checa, A.G., Gale, J.D., Gebauer, D., Sainz-Díaz, C.I., 2012. Calcium carbonate polyamorphism and its role in biomineralization: How many amorphous calcium carbonates are there? Angew. Chem. Int. Ed. 2012 (51), $2-13$.

Checa, A.G., Rodríguez-Navarro, A.B., 2005. Self-organisation of nacre in the shells of Pterioida (Bivalvia: Mollusca). Biomaterials 26, 1071-1079.

Checa, A.G., Sánchez-Navas, A., Rodríguez-Navarro, A., 2009. Crystal growth in the foliated aragonite of monoplacophorans (Mollusca). Cryst. Growth Des. 9, 4574-4580.

Checa, A.G., Cartwright, J.H.E., Willinger, M.-G., 2011. Mineral bridges in nacre. J. Struct. Biol. 176, 330-339.

Dalbeck, P., England, J., Cusack, M., Lee, M.R., Fallick, A.E., 2006. Crystallography and chemistry of the calcium carbonate polymorph switch in M. edulis shells. Eur. J. Mineral. 18, 601-609.

Dauphin, Y., 2001. Nanostructures de la nacre des tests de céphalopodes actuels. Paläont. Z. 75, 113-122.

Dauphin, Y., 2006. Structure and composition of the septal nacreous layer of Nautilus macromphalus L. (Mollusca, Cephalopoda). Zoology 109, 85-95.

Dauphin, Y., 2008. The nanostructural unity of mollusk shells. Mineral. Mag. 72, 243-246.

Dauphin, Y., Dufour, E., 2008. Nanostructures of the aragonitic otolith of cod (Gadus morhua). Micron 39, 891-896.

England, J. Cusack, M., Dalbeck, P., Pérez-Huerta, A., 2007. Comparison of the crystallographic structure of semi nacre and nacre by electron backscatter diffraction. Cryst. Growth Des. 7, 307-310.

Freer, A., Greenwood, D., Chung, P., Claire, .L., Pannell, C.L., Cusack, M., 2010. Aragonite prism-nacre interface in freshwater mussels Anodonta anatina (Linnaeus, 1758) and Anodonta cygnea (L. 1758). Cryst. Growth Des. 10, 344347.

Gilbert, P.U.P.A., 2012. Polarization-dependent Imaging Contrast (PIC) mapping reveals nanocrystal orientation patterns in carbonate biominerals. J. Electron Spectrosc. Related Phenom. 185, 395-405.

Gilbert, P.U.P.A., Metzler, R.A., Zhou, D., Scholl, A., Doran, A., Young, A., Kunz, M., Tamura, N., Coppersmith, S.N., 2008. Gradual ordering in red abalone nacre. J. Amer. Chem. Soc. 130, 17519-17527.

Gilow, C., Zolotoyabko, E., Paris, O., Peter Fratzl, P., Aichmayer, B., 2011. Nanostructure of biogenic calcite crystals: A view by small-angle X-ray scattering. Cryst. Growth Des. 11, 2054-2058.

Gong, Y.U.T., Killian, C.E., Olson, I.C., Appathurai, N.P., Amasino, A.L., Martin, M.C., Holt, L.J., Wilt, F.H., Gilbert, P.U.P.A., 2012. Phase transitions in biogenic amorphous calcium carbonate. Proc. Natl. Acad. Sci. USA 109, 6088-6093.

Grégoire, C., 1962. On submicroscopic structure of Nautilus shell. Bull. Inst. Roy. Sci. Nat. Belgique 38, 1-71.

Gries, K., Kröger, R., Kübel, C., Schowalter, M., Fritz, M., Rosenauer, A., 2009. Correlation of the orientation of stacked aragonite platelets in nacre and their connection via mineral bridges. Ultramicroscopy 109, 230-236.

Griesshaber, E., Schmahl, W.W., Ubhi, H.S., Huber, J., Nindiyasari, F., Maier, B., Ziegler, A, in press. Homoepitaxial meso- and microscale crystal co-orientation and organic matrix network structure in Mytilus edulis nacre and calcite. Acta Biomater. (available online 27 July 2013).

Horcas, I., Fernández, R., Gómez-Rodríguez, J.M., Colchero, J., Gómez-Herrero, J., et al., 2009. WSXM: A software for scanning probe microscopy and a tool for Nanotechnology. Rev. Sci. Instrum. 78, 013705. 
Huang, Z.W., Li, X.D., 2012. Order-disorder transition of aragonite nanoparticles in nacre. Phys. Rev. Lett. 109, 025501.

Li, X.D., Huang, Z.W., 2009. Unveiling the formation mechanism of pseudo-single crystal aragonite platelets in nacre. Phys. Rev. Lett. 102, 075502.

Li, X.D., Chang, W.C., Chao, Y.J., Wang, R.Z., Chang, M., 2004. Nanoscale structural and mechanical characterization of a natural nanocomposite material - the shell of red abalone. Nano Lett. 4, 613-617.

Li, X.D., Zhu, Z.-H., Wang, R.Z., 2006. In situ observation of nanograin rotation and deformation in nacre. Nano Lett. 6, 2301-2304.

Li, H., Xin, H.L., Kunitake, M.E., Keene, E.C., Muller, D.A., et al., 2011. Calcite prisms from mollusk shells (Atrina rigida): Swisscheese-like organic-inorganic singlecrystal composites. Adv. Funct. Mater. 21, 2028-2034.

Metzler, R.A., Abrecht, M., Olabisi, R.M., Ariosa, D., Johnson, C.J., Frazer, B.H. Coppersmith, S.N., Gilbert, P.U.P.A., 2007. Architecture of columnar nacre, and implications for its formation mechanism. Phys. Rev. Lett. 98, 268102.

Metzler, R.A., Zhou, D., Abrecht, M., Chiou, J.-W., Guo, J., Ariosa, D., Coppersmith, S.N., Gilbert, P.U.P.A., 2008. Polarization-dependent imaging contrast in abalone shells. Phys. Rev. B 77, 064110.

Mutvei, H., 1969. On the micro- and ultrastructures of the conchiolin in the nacreous layer of some recent and fossil molluscs. Stockholm Contr. Geol. 22, 1 17.

Mutvei, H., 1970. Ultrastructure of the mineral and organic components of molluscan nacreous layers. Biomineralization 2, 49-72.

Mutvei, H., 1972a. Ultrastructural relationships between the prismatic and nacreous layers in Nautilus (Cephalopoda). Biomineralization 4, 81-86.

Mutvei, H., 1972b. Formation of nacreous and prismatic layers in Mytilus edulis L. (Lamellibranchiata). Biomineralization 6, 96-100.

Mutvei, H., 1977. The nacreous layer in Mytilus, Nucula and Unio (Bivalvia). Calcif. Tissue Res. 24, 11-18.

Mutvei, H., 1978. Ultrastructural characteristics of the nacre in some gastropods. Zool. Scripta 7, 287-296.

Mutvei, H., 1979. On the internal structure of the nacreous tablets in molluscan shells. Scanning Electron Microsc. II 1979, 457-462.

Mutvei, H., 1980. The nacreous layer in molluscan shells. In: Omori, M., Watabe, N. (Eds.), The Mechanisms of Biomineralization in Animals and Plants. Tokai University Press, Tokyo, pp. 49-56.

Mutvei, H. 1984. Ultrastructural research on molluscan nacre. In: Proceedings of the 27th International Geological Congress Moscow, Russia. VNU Science Press BV. Utrecht, The Netherlands, pp. 111-124.

Mutvei, H., 1991. Using plasma-etching and proteolytic enzymes in studies of molluscan shell ultrastructure. In: Suga, S., Nakahara, H. (Eds.), Mechanisms and Phylogeny of Mineralization in Biological Systems. Springer, Tokyo, pp. $157-$ 160.

Mutvei, H., Dunca, E., 2008. Structural relationship between interlamellar organic sheets and nacreous tablets in gastropods and cephalopod Nautilus. Paläontol. Z. 82, 85-94.

Mutvei, H., Dunca, E., 2010. Crystalline structure, orientation and nucleation of the nacreous tablets in the cephalopod Nautilus. Paläontol. Z. 84, 457-465.

Nassif, N., Pinna, N., Gehrke, G., Antonietti, M., Jäger, C., et al., 2005. Amorphous layer around aragonite platelets in nacre. Proc. Natl. Acad. Sci. USA 102, 12653 12655.

Nelyubina, Y.V., Lyssenko, K.A., 2012. From "loose" to "dense" crystalline phases of calcium carbonate through "repulsive" interactions: An experimental chargedensity study. Chem. Eur. J. 18, 12633-12636.

Nouet, J., Baronnet, A., Howard, L., 2012. Crystallization in organo-mineral microdomains in the crossed-lamellar layer of Nerita undata (Gastropoda, Neritopsina). Micron 43, 456-462.
Nudelman, F., Chen, H.H., Goldberg, H.A., Weiner, S., Addadi, L., 2007. Lessons from biomineralization: comparing the growth strategies of mollusc shell prismatic and nacreous layers in Atrina rigida. Faraday Discuss. 136, 9-25.

Okumura, T., Suzuki, M., Nagasawa, H., Kogure, T., 2010. Characteristics of biogenic calcite in the prismatic layer of a pearl oyster, Pinctada fucata. Micron 41, 821 826.

Okumura, T., Suzuki, M., Nagasawa, H., Kogure, T., 2011. Microstructural variation of biogenic calcite with intracrystalline organic macromolecules. Cryst. Growth Des. 12, 224-230.

Olson, I.C., Kozdon, R., Valley, J.W., Gilbert, P.U.P.A., 2012. Mollusk shell nacre ultrastructure correlates with environmental temperature and pressure. J. Amer. Chem. Soc. 134, 7351-7358.

Olson, I.C., Metzler, R.A., Tamura, N., Kunz, M., Killian, C.E., Gilbert, P.U.P.A. in press. Crystal lattice tilting in prismatic calcite. J. Struct. Biol. (available online 24 June 2013).

Politi, Y., Metzler, R.A., Abrecht, M., Gilbert, B., Wilt, F.H., et al., 2008. Transformation mechanism of amorphous calcium carbonate into calcite in the sea urchin larval spicule. Proc. Natl. Acad. Sci. USA 105, 17362-17366.

Przeniosło, R., Stolarski, J., Mazur, M., Brunelli, M., 2008. Hierarchically structured scleractinian coral biocrystals. J. Struct. Biol. 161, 74-82.

Rousseau, M., Lopez, E., Stempflé, P., Brendlé, M., Franke, L., et al., 2005. Multiscale structure of sheet nacre. Biomaterials 26, 6254-6262.

Schmidt, W.J., 1922. Über den Aufbau der Schale von Nucula. Archiv Mikroskop. Anatom. 96, 171-181.

Schmidt, W.J., 1923. Bau und bildung der Perlmuttermasse. Zool. Jahrb. Zool. Abt. 96, 1-148.

Schmidt, W.J., 1924. Die Bausteine des Tierkörpers in polarisiertem Lichte. Verlag F, Cohen, Bonn.

Schöne, B.R., Dunca, E., Fiebig, J., Pfeiffer, M., 2005. Mutvei's solution: an ideal agent for resolving microgrowth structures in biogenic carbonates. Palaeogeogr. Palaoclimatol. Palaeoecol. 228, 149-166.

Sethmann, I., Hinrichs, R., Wöhrheide, G., Putnis, A., 2006. Nano-cluster composite structure of calcitic sponge spicules -A case study of basic characteristics of biominerals. J. Inorg. Biochem. 100, 88-96.

Seto, J., Ma, Y., Davis, S.A., Meldrum, F., Gourrier, A., et al., 2012. Structure-property relationships of a biological mesocrystal in the adult sea urchin spine. Proc. Natl. Acad. Sci. USA 109, 3699-3704.

Wada, K., 1961. Crystal growth of molluscan shells. Bull. Natl. Pearl Res. Lab. 7, 703 828 .

Wada, K., 1972. Nucleation and growth of aragonite crystals in the nacre of some bivalve molluscs. Biomineralization 6, 141-159.

Weiner, S., Addadi, L., 2011. Crystallization pathways in biomineralization. Annu. Rev. Mater. Res. 41, 21-40.

Wise, S.W., 1970. Microarchitecture and mode of formation of nacre (mother of pearl) in pelecypods, gastropods and cephalopods. Eclogae geol. Helv. 63, 775797.

Wolf, S.E., Lieberwirth, I., Natalio, F., Bardeau, J.-F., Delorme, N., Emmerling, F., Barrea, R., Kappl, M., Marin, F., 2012. Merging models of biomineralisation with concepts of nonclassical crystallisation: is a liquid amorphous precursor involved in the formation of the prismatic layer of the Mediterranean Fan Mussel Pinna nobilis? Faraday Discuss. 159, 433-448.

Younis, S., Kauffmann, Y., Bloch, L., Zolotoyabko, E., 2012. Inhomogeneity of nacre lamellae on the nanometer length scale. Cryst. Growth Des. 19, 4574-4579.

Zhang, G.S., Li, X.D., 2012. Uncovering aragonite nanoparticle self-assembly in nacre - A natural armor. Cryst. Growth Des. 12, 4306-4310. 